\title{
EM BUSCA DE UMA TEORIA SINTÁTICA TEMPORAL PARA AS ENCAIXADAS DO PORTUGUÊS BRASILEIRO*
}

Sandra Mara Silvério**

\section{Introdução}

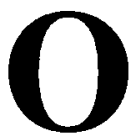

$s$ estudos existentes na tradição semântica definem o "Tempo" de formas variadas: "Tempo" é um operador sentencial denotando o tempo em que a verdade da sentença está sendo avaliada; é uma expressão referencial denotando o tempo de um evento ou situação; é um predicado temporal análogo ao verbo. É nesse panorama semântico que, em termos mais específicos, se situam as teorias dedicadas à distribuição e à interpretação de formas temporais particulares.

Na teoria gerativa dos anos 80 , o termo "Tempo" referia-se à flexão temporal de um verbo em sua forma finita, locado em $\mathrm{I}^{\circ}$, núcleo de IP. Entretanto, a própria inclusão, na Teoria X-barra, de uma categoria máxima, TP, Tense Phrase (Pollock, 1989), põe em discussão muito mais do que a simples afixação

* Parte deste trabalho foi utilizado no projeto pleiteando uma bolsa RD do CNPq (processo n..$^{\circ}$ 300751/01-0).

** Professora Doutora CNPq/UFPR. 
morfológica na estrutura frasal; antes, abre perspectivas para que se possa buscar uma descrição e uma explicação sintáticas da distribuição do "Tempo" sem desconsiderar sua interpretação.

Uma perspectiva plausível com esta finalidade é o trabalho desenvolvido por Stowell $(1993 ; 1994)$ que se propõe a reduzir muitos dos estudos semânticos sobre o "Tempo" a princípios de teoria sintática motivados independentemente. ${ }^{1}$ Entretanto, embora a proposta de Stowell consiga derivar, via "controle", a regra $S \mathrm{~T}^{2}$ para o inglês, ela desconsidera características importantes do nosso "sistema tempo-aspectual": diferente do inglês, em Português brasileiro (doravante PB), a morfologia flexional tem papel relevante e o fenômeno SOT, por exemplo, não pode receber o mesmo tratamento.

Como parte de um projeto maior que busca descrever e explicar adequadamente os diversos contrastes temporais, este trabalho tem como objetivo observar a possível aplicação da proposta de Stowell em sentenças do PB, bem como trazer para a discussão outras contribuições que, de alguma forma, ampliem o corpo de fenômenos a ser avaliado. A primeira parte traz uma exposição da sintaxe de tempo postulada pelo autor; a segunda parte procura observar esta teoria à luz dos dados do PB. Finalmente, nas considerações finais, é feito um breve levantamento dos fenômenos observados, dos resultados da aplicação da teoria e das vias alternativas que podem ser seguidas em trabalhos posteriores.

\section{A sintaxe do tempo de Stowell}

Para introduzir a teoria de Stowell, tomemos a seguinte sentença:

A Maria lamentou esta situação.

1 A teoria de Stowell segue a versão LGB do modelo de Princípios e Parâmetros, tentando derivar as propriedades do sistema lingǘstico neste arcabouço térico, que compreende a interpretação da estrutura argumental, funções temáticas e referência pronominal.

2 O fenômeno SOT (ou Sequiência de Tempo) se refere a uma situação em que um morfema de tempo passado ocorre imediatamente encaixado sob um outro tempo passado, mas este passado, na encaixada, pode ser interpretado como simultâneo ao tempo passado da oração matriz, como acontece em John heard that Mary was pregnant (o Joāo ouviu que a Maria estava grávida) - de Enç (1987, p. 635). 
Numa perspectiva semântica, o pretérito perfeito é usado para localizar um evento num tempo passado. Em outras palavras, o tempo de um evento ou situação associado com o verbo temático (Tempo do Evento, ou E), isto é, o tempo em que a Maria lamenta, é localizado como anterior ao tempo em que a sentença é falada (o Tempo da Fala, ou S). ${ }^{3}$

Na teoria desenvolvida por Stowell, estas relações de ordenação temporal se refletem na sintaxe. Por isso, TEMPO ${ }^{4}$ é dividido sintaticamente em seus componentes semânticos. "TEMPO é um núcleo predicador diádico, tomando dois argumentos denotadores de tempo" (trad. livre, Stowell, 1994, p. 5); cada um desses argumentos denotará algum tempo. Na posição de argumento interno, Stowell localiza o Tempo de Evento (E). E, como outros tipos de expressões referenciais, os argumentos de "Tempo" estão sujeitos à Teoria da Ligação.

Considerando as relações de ordenação temporal, o autor assume que a "função semântica primária de TEMPO é localizar no tempo a denotação de E em relação à denotação de seu argumento externo" (trad. livre de Stowell, 1994, p. 5). Assim, em (1), T' atribui um traço [+ PASSADO] a seu argumento interno, sendo que a noção de passado reside no próprio T, na forma de PASSADO ("depois").

Neste ponto, é necessário localizar a posição do argumento interno de TEMPO no esquema $X$-barra. Stowell propõe então uma nova categoria funcional, ZP ("Zeit-Phrase"), que serve como o argumento interno de $\mathrm{T}^{\circ}$, localizada entre TP e VP, e que denota tempo. Como uma categoria análoga à categoria DP, que mantém uma relação com NP, ZP mantém uma relação com VP, através da vinculação por algum elemento do ZP de uma variável localizada numa posição adjunta a VP. ${ }^{6}$

Quanto ao argumento temporal externo, Stowell, seguindo Zagona (1990, citada por Stowell, 1993, p. 7), postula sua origem na posição Spec TP, embora não atribua ao argumento a denotação do Tempo $S$. Em vez disso, a função

3 O $S$ foi mantido do termo em inglês Speech Time.

4 a) Stowell diferencia graficamente os termos tempo, em minúsculas, que deve ser entendido como seu uso informal, de TEMPO, o núcleo $\mathrm{T}^{\circ}$ da categoria TP na Teoria $\mathrm{X}$ barra. O mesmo se aplica a passado e presente: enquanto passado, em minúsculas, será usado sempre que se fizer referência ao tempo enquanto afixo morfologico, de maneira informal, PASSADO deve ser entendido como uma instância de TEMPO $\left(\mathrm{T}^{\circ}\right)$, o núcleo de TP na Teoria $\mathrm{X}$-barra.

b) Com respeito ainda ao vocábulo tempo, assumo a responsabilidade de eventuais ambigüidades, uma vez que o inglês possui duas formas distintas, tense e time, para a forma tempo do PB.

5 Stowell segue, em parte, as idéias de Zagona (1990, apud Stowell, 1994, p. 4).

6 Essa posição, segundo Stowell, corresponde ao argumento eventual "externo" postulado por Kratzer (1989; apud Stowell, 1993, p. 10). Em Larson (1988), a variável ZP estaria localizada no Spec do VP mais alto. 
temática atribuída ao argumento externo é a de Tempo de referência (R), não necessariamente identificada com o Tempo $S$, o que é justificado pelo fato de que, em sentenças simples, como a em (1), o Tempo $R$ denota efetivamente o Tempo $S$, mas, em geral, $R$ denota o Tempo $E$ da sentença matriz em sentenças subordinadas, como se verá adiante.

Dados esses pressupostos, uma sentença como a apresentada em (1), A Maria lamentou esta situação, de acordo com Stowell, tem a representação estrutural:

(2)

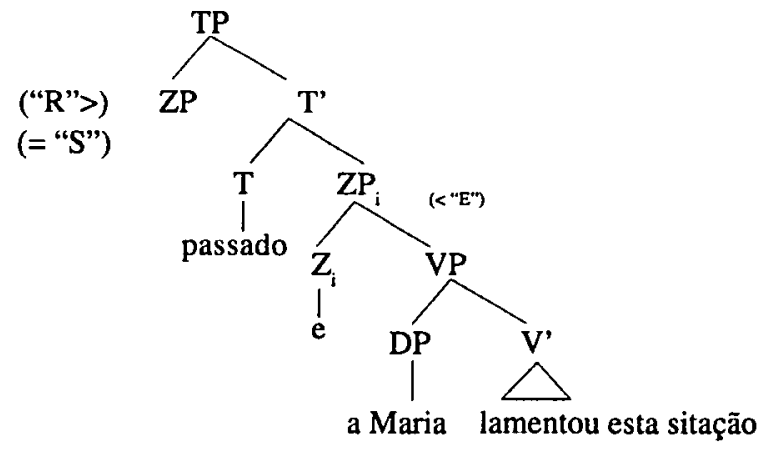

Em (2), o argumento ZP externo de PASSADO é o Tempo R (no caso, igual a S); o argumento interno de ZP denota o Tempo E; e PASSADO estabelece a ordenação entre estes dois tempos. Podemos ler a estrutura como: O Tempo da fala está depois de um tempo ZP em que a Maria lamenta a situação (cf. representação, exemplo e leitura equivalentes em Stowell, 1994, p. 7).

Para integrar sua proposta à Teoria X-barra, Stowell precisa ainda definir a categoria vazia em Spec de ZP. ${ }^{7}$ Acrescenta, então, que a denotação do Tempo de referência, argumento externo, é fixada pela Teoria do controle. Quando PASSADO ocorre numa sentença simples, como a em (2), seu Tempo R externo é um PRO-ZP, sem qualquer outro ZP que o c-comande e que possa servir como seu controlador. O Tempo $S$ pode, desta forma, indexicá-lo.

Quando ZP ocorre numa sentença encaixada, como em (3)

7 Stowell precisa assumir que TP contém não só [Spec, TP], a posição não-temática ocupada pelo sujeito tradicional, mas também uma posição Spec não-temática para o argumento ZP. Disto segue que ambas as posições são tomadas como insensíveis aos efeitos dos cruzamentos sintáticos. 
(3) A Maria lamentou [que o João foi embora].

PRO-ZP é controlado (porque c-comandado) pelo ZP mais próximo, ou melhor, pela variável saturada do núcleo $\mathrm{Z}^{\circ}$ do $\mathrm{ZP}$ matriz de Tempo do evento, como em (4):

(4)

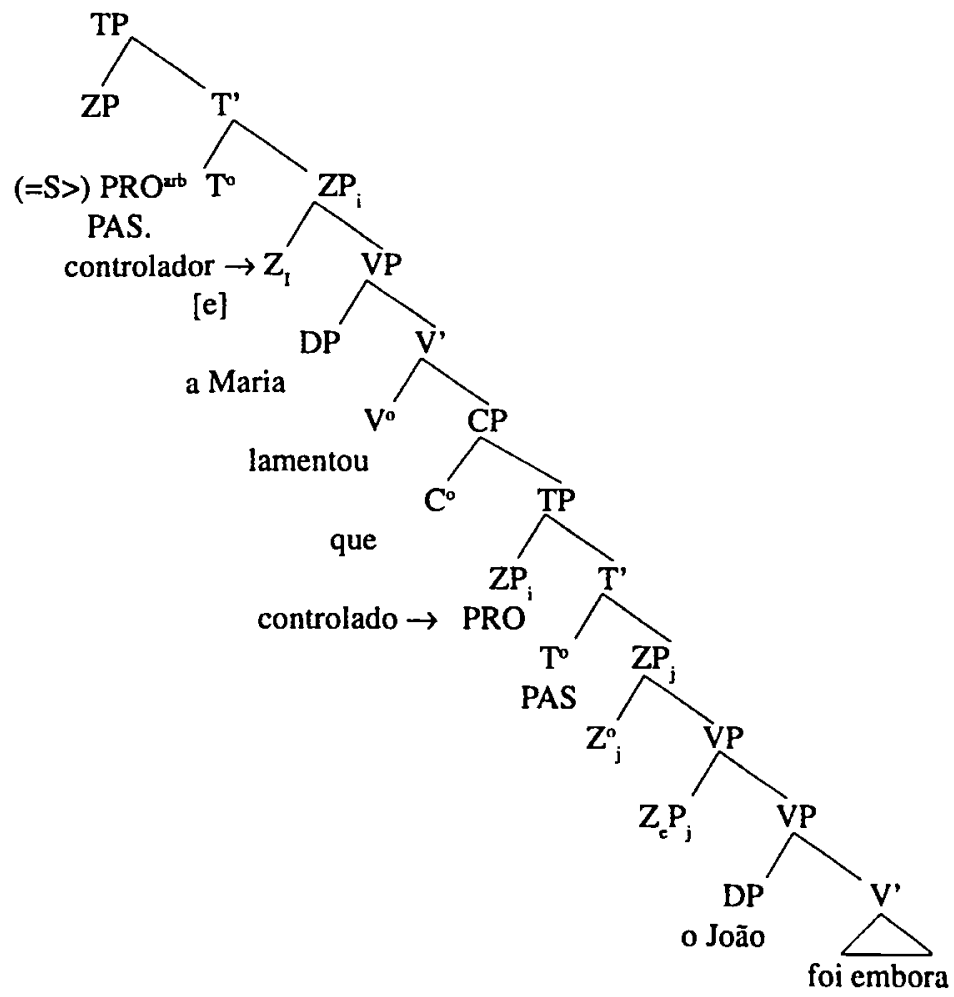

Em (4), estamos diante de uma leitura anterior (no original, "shifted" tense construal): o Tempo E da encaixada é fixado em relação ao tempo ao Tempo E da sentença matriz. A leitura da estrutura em (4) é: O Tempo da fala está depois de um tempo $\mathrm{ZP}_{\mathrm{i}}$, aquele em que Maria lamenta, que está depois de um tempo $\mathrm{ZP}_{\mathrm{j}}$ em que o João vai embora (estrutura e leitura equivalentes as de Stowell, 1994, p. 9). 
Entretanto, a interpretação de sentenças encaixadas que contêm verbos estativos no passado, como a que se encontra em (5), acaba trazendo um proble$\mathrm{ma}^{8}$ para a teoria proposta por Stowell:

(5) John said that Bill was sick (ex. 8 de Stowell, 1994,p. 18). /John disse que Bill estava doente/

Em (5), a encaixada no passado pode ser interpretada de duas maneiras: primeiro, a sentença é anterior ao tempo em que "John disse". A leitura anterior é possível desde que o fato contido aí, "a doença de Bill", seja tomado como um tópico no contexto discursivo.

O problema maior é a segunda possibilidade de interpretação, a leitura simultânea, ou seja, aquela em que o Tempo $E$ da subordinada pode ser tomado como ocorrendo em tempo paralelo ao $\mathrm{E}$ da sentença matriz. Esse fenômeno é chamado, na semântica, de sequiência de tempo (SOT) e é facilmente observado quando o passado no discurso indireto corresponde ao presente no discurso direto (John said: "Bill is sick").

A leitura simultânea é problemática para a teoria de Stowell porque o argumento temporal do verbo matriz (marcado PASSADO) controla o Tempo de referência da sentença encaixada e ordena os tempos com a relação "depois de", não com a relação "simultâneo a".

A fim de acomodar dentro da proposta esta leitura simultânea, Stowell revê sua teoria, no sentido de admitir ou verificar o que significa, na realidade, o tempo passado, isto é, se a conexão entre passado e PASSADO é necessária / obrigatória.

Surgem daí algumas suposições: a) no inglês, passado é uma instância de $\mathrm{Z}$ e não de $\mathrm{T}$; b) portanto, $\mathrm{Z}$ é visível (overt), altemando entre passado e presente; c) e $\mathrm{T}$ é invisível (nonovert), pelo menos com respeito aos núcleos PASSADO e PRESENTE. Tendo em mente tais pressupostos, Stowell oferece estas opções: a) a sentença encaixada não contém em T a ocorrência de PASSADO e, portanto, o tempo E desta encaixada não pode ser ordenado como anterior a outro tempo; b) o T da encaixada pode conter um PRESENTE nulo; c) ou, seguindo Enç (1990, citada por Stowell, 1994, p. 19), que o T nulo da subordinada é livre para escolher entre PASSADO e PRESENTE. Se esta última é a opção

8 a) Conferir também a mesma discussão em Enç (1987, p. 635).

b) $\mathrm{O}$ exemplo foi mantido em inglês porque o $\mathrm{PB}$, como se verá, parece ter aí uma outra descrição. 
selecionada, o resultado seria a leitura simultânea; se a opção for passado, a leitura anterior é que é a obtida.

Mas se a morfologia de passado não significa a presença de PASSADO em $\mathrm{T}^{\circ}$ da mesma sentença, por que, no caso de sentença simples, como a em (1), o Tempo E sempre é entendido como anterior ao Tempo R (ou Tempo S)? Stowell recoloca, então, a sugestão de o tempo do evento, $\mathrm{ZP}$, ser interpretado como um DP definido ou indefinido. Esta analogia $\operatorname{com} Z^{\circ}$ e $D^{\circ}$, de forma mais articulada, leva-o à comparação entre "presente" e "passado" com os determinantes quantificadores algum e nenhum, distintos um do outro sobretudo por suas propriedades de escopo (nenhum, any, deve aparecer em LF sob o escopo de Negação ou outro item de polaridade; enquanto algum, some, deve aparecer fora do escopo de qualquer elemento de polaridade). ${ }^{9}$

Tal como any, Stowell propõe que o passado seja tomado como um tipo de elemento de polaridade, com uma posição de escopo em LF fixada sob PASSADO; "passado" é, portanto, um Item de Polaridade sensivel a PASSADO (PPI, do original PAST Polarity Item). Assim, toda vez que passado ocorre como o núcleo de um ZP de tempo do evento em uma sentença simples, esta sentença deve conter PASSADO em T ${ }^{\circ}$, ou o PPI não pode ser licenciado. A encaixada, por seu turno, pode conter livremente ou PASSADO (nulo) ou PRESENTE (nulo) em seu $\mathrm{T}^{\circ}, \mathrm{e}$ é isso que permite a ambigüidade entre a leitura anterior e a leitura simultânea. Por outro lado, como some, "presente" é um "anti-PPI" e não pode ocorrer sob o escopo de PASSADO; uma sentença encaixada contendo morfologia de tempo presente de um verbo finito deve ser entendida como contendo um PRESENTE (nulo) em T .

\section{A sintaxe de tempo e o PB}

Diferentemente do inglês, o PB apresenta, sem dúvida, um número maior de tempos e modos marcados morfologicamente com "passado", o que a princípio parece colocar algumas dificuldades com relação à descrição e à explicação de uma sintaxe do tempo.

No entanto, essa dificuldade é apenas aparente, pois a presença de morfologia visível pode acabar ajudando a tornar o sistema muito mais previsível e de explicação mais simples. Como na proposta de Stowell, a discussão

9 Cf. Ladusaw (1979, apud Stowell, 1984, p. 20). 
parece concentrar-se nas subordinadas, observe-se, em (6), uma sentença no pretérito imperfeito do indicativo na encaixada:

(6) A Maria disse que o João estava doente.

Em (6), o problema com o qual se deparou Stowell, em (5), é verificável, mas questionável no caso de línguas que apresentam morfologia tempoaspectual. Há realmente, como se pode verificar, a possibilidade de duas leituras: a primeira, uma leitura de anterioridade - o tempo da doença de João é anterior ao tempo do dizer da Maria. A segunda leitura, a simultânea, pode ser obtida transformando-se o discurso indireto em direto: A Maria disse: "O João está doente". Nesta leitura, o tempo em que o João esteve doente deve ser tomado como simultâneo ao tempo do dizer da Maria.

Mas, se de um lado a possibilidade das duas leituras existe, de outro lado, é questionável a legitimidade do teste de transformação de discurso direto em indireto para a obtenção da leitura simultânea. Do ponto de vista semântico e sintático, cada uma dessas formas possui propriedades diferenciadas como a ligação pronominal e a alteração do tempo da oração encaixada (cf. Kuno, 1997). Em PB, por exemplo, o verbo da encaixada precisa exibir morfologia do imperfeito para a sentença apresentar essa dupla possibilidade de leitura. Assim, o que está sendo tomado como simultâneo é a possibilidade de o estado de doença de João perdurar até o momento em que a Maria diz. O problema, então, parece situar-se no eixo aspectual, não no temporal, e/ou nas propriedades de aspecto (aktionsart) do predicado.

Tome-se o "teste" de transformação discurso indireto $\rightarrow$ direto tradicionalmente utilizado como válido para esta investigação. Compare-se (6), repetida abaixo, com (7), onde o tipo de predicado na encaixada é uma atividade:

a. A Maria disse que o João estava doente.

b. A Maria disse: "o João está doente".

a. A Maria contou que o Ricardo brincava de boneca.

b. A Maria contou: "O Ricardo brinca/ está brincando de boneca".

O exemplo (7b) não pode ser utilizado como boa paráfrase para a sentença em (7a). Em (7a), além da leitura simultânea como expressa em (7b), existem outras duas possibilidades de interpretação: 
$1^{\circ}$ ) o evento "brincar de boneca" é simultâneo ao contar da oração principal e os dois eventos se situam no passado em relação ao tempo da fala;

$2^{a}$ ) o evento "brincar de boneca" é anterior ao evento "contar" da oração principal.

Estas mesmas leituras podem ser encontradas em (6a), embora a última possibilidade seja preferencialmente expressa com a morfologia do perfeito: $A$ Maria disse que o João esteve doente.

Por fim, note-se principalmente que, com o discurso direto, os eventos da encaixada são verdadeiros também se avaliados como simultâneos ao tempo da fala, interpretação não encontrada em (6a) e (7a). Portanto, a transformação discurso indireto $\rightarrow$ discurso direto não é um "teste" confiável, dada a interpretação temporal de simultaneidade com o tempo $S$ presente apenas em (6b) e (7b).

Quanto ao aspecto presente na morfologia verbal, vejamos as demais formas verbais para expressar o passado que o $\mathrm{PB}$ possui - o pretérito perfeito em (8) e o pretérito mais-que-perfeito em (9):

a. A Maria disse que o João esteve doente.

b. A Maria disse: "O João esteve / estava / *está doente."

a. A Maria disse que o João tinha estado doente.

b. A Maria disse: "O João esteve / estava / *está doente.

O exemplo em (8b) com o presente não serve como paráfrase para a sentença em (8a). Parece que a morfologia de aspecto perfectivo (introduzindo a eventualidade como fechada), mesmo em se tratando de um estativo, não permite que se alongue o estado de doença de João até o momento do dizer de Maria. Tal observação também é verdadeira com o pretérito mais-que-perfeito na encaixada (9a), em que a doença de João é interpretada como anterior ao tempo do dizer. E mais: em (8b) e (9b), o uso do imperfeito só serve como paráfrase para (8a) e (9a) se excluirmos a leitura em que o evento da encaixada for simultâneo ao evento da oração principal.

Seguindo a formulação de Stowell (1994), na explicação para o fenômeno SOT, a morfologia tempo-aspectual deveria ser irrelevante para a interpretação das sentenças, ou seja, (6) e (8) deveriam ter a mesma representação (e, portanto, as mesmas interpretações) em LF, já que em todos esses exemplos "passado" se encontra sob escopo de PASSADO. No entanto, o fato de as sentenças (6) a (8) não terem a mesma interpretação mostra que a teoria de Stowell falha, porque sua proposta de representação estrutural não leva em conta a morfologia aspectual. Em PB, as flexões verbais de passado, sincréticas por denotarem 
também aspecto, implicam interpretações diferentes, portanto, tais flexões não podem ser tomadas como nulas em SS ou em LF.

Aliás, partir de uma definição de tempo enquanto intervalo pode ser uma solução plausível para se construir uma sintaxe tempo-aspectual. ${ }^{10}$ Resta saber se existe possibilidade de termos uma teoria abstrata o suficiente que possa captar nuances temporais e aspectuais que, de certa forma, acabam se diluindo por toda a sentença.

\section{Considerações finais}

Muitas investigações ainda precisam ser realizadas para explicar as propriedades sintáticas e semânticas temporais presentes nas línguas naturais. Inicialmente, é necessário um levantamento mais apurado de restrições das combinações temporais em períodos subordinados que tragam um quadro mais nítido dos fenômenos aspectuais aí atuantes.

Em particular, na proposta de Stowell, destacam-se os problemas causados pela co-existência de uma leitura anterior e de uma leitura simultânea em sentenças do inglês. Essa duplicidade de leitura parece, num primeiro momento, ligada ao fato de o argumento temporal da sentença matriz controlar o Tempo $R$ da sentença encaixada e tornar a interpretação vinculada à "depois de" e não vinculada à "simultâneo a". Isto, entretanto, não quer dizer que não exista um controle da matriz sobre a encaixada; antes, equivale a dizer que talvez se tenha tomado o "controlador" errado para precisar adequadamente o tipo de "subordinação" temporal que a sentença matriz exerce sobre o argumento interno sentencial selecionado.

Nesse sentido, o tratamento de fenômenos como o SOT refletem as dificuldades a serem enfrentadas ao se propor uma integração de fenômenos aspectuais a fenômenos temporais. Em particular, a questão aspectual é relevante para o PB: diferentemente do inglês, é a morfologia do imperfeito que pode gerar a duplicidade de leituras (simultânea e anterior). Não seria este o efeito interpretativo esperado quando o tempo da encaixada é o imperfeito, que denota o evento como não-fechado? Se, todavia, o objetivo básico de Stowell é reduzir

10 Cf. Enç (1987), para quem a interpretação de intervalo é relevante na explicação do fenômeno SOT, interpretação que a representação sintática de Stowell não consegue derivar. 
os estudos semânticos sobre o "Tempo" a princípios de teoria sintática motivados independentemente, então, outros caminhos devem ser traçados.

Um desses caminhos, envolvendo o arcabouço teórico da semântica, pode estar em tomar o "Tempo" não como um operador sentencial, mas, seguindo Enç (1987), como uma expressão referencial denotando intervalos. Uma perspectiva assim possibilitaria, por exemplo, a inserção na estrutura proposta por Stowell de traços como [+ perfectivo] ou [+ imperfectivo] no tempo da encaixada a fim de se buscar as restrições interpretativas destes traços em LF. Como intervalo, um tempo marcado [+ imperfectivo] pode ser tomado como sendo o evento matriz ordenado com relação a "depois de", desde que não interpretado como o "depois de" concluído. Desta forma, em sentenças como (5), não se exclui a leitura em que John disse num tempo passado que Bill estava doente num tempo anterior a este, desde que o tempo de doença de Bill possa ser tomado como um intervalo, durativo, ou sem fim especificado, que se estende até o tempo do dizer de John.

Outro caminho, envolvendo o modelo teórico (sintático) adotado, é pensar a morfologia como o lugar de diferenças entre as línguas (Chomsky, 1995). A utilização de derivações diferenciadas para cada sentença em particular permitiria conciliar os traços tempo-aspectuais citados acima com a morfologia que cada língua exibe. Em outras palavras, assumir um outro modelo teórico talvez desse conta de descrever e explicar, sem postulações ou categorias adicionais, não só a sintaxe tempo-aspectual de línguas românicas (o português e o italiano, por exemplo) como também a do inglês que, naturalmente, exibe fenômenos interpretativos como o SOT por apresentar morfologia flexional visivelmente reduzida.

Finalmente, numa postura que não quer desmerecer a proposta de Stowell, mas torná-la válida por ser também a intuição que se seguirá, fica a encargo de um trabalho futuro a tarefa de propor uma teoria que possa dar conta dos diversos fatores semânticos e sintáticos que precisam ser considerados quando o assunto é a ordenação temporal nas línguas naturais.

\section{RESUMO}

Este artigo é parte de um projeto maior que busca descrever e explicar adequadamente os contrastes temporais em sentenças raízes e encaixadas do Português brasileiro. Para isto, ele traz uma exposição e uma avaliação da sintaxe de tempo postulada por 
Stowell $(1993 ; 1994)$, para quem é possível derivar os estudos semânticos sobre tempo de princípios de teoria sintática motivados independentemente.

Palavras-chave: gramática gerativa, sintaxe temporal, tempos verbais.

\section{ABSTRACT}

This paper is part of a larger project which attempts to describe and explain adequately the temporal contrasts in Brazilian Portuguese embedded and root sentences. It conducts a presentation and an evaluation of tense syntax as postulated by Stowell $(1993 ; 1994)$, according to whom it is possible to derive semantic studies on tense from independently motivated syntactic theory principles.

Key-words: generative grammar, tense syntax, verb tenses.

\section{REFERÊNCIAS}

CÂMARA JÚNIOR, J. M. Estrutura da Língua Portuguesa. 23. ed. Petrópolis: Vozes, 1970.

CHOMSKY, N. The minimalist program. Cambridge, Massachusetts: The MIT Press, 1995.

ENÇ, M. Anchoring conditions for tense. Linguistic Inquiry, v. 18, n. 4, p. 633-657, 1987.

KUNO, S. Functional Syntax. Anaphora, discourse and empathy. Chicago: The University of Chicago Press, 1997.

LARSON, R. On the double object construction. Linguistic Inquiry, v. 19, n. 3, p. 335$392,1988$.

PARSONS, T. Events in the semantics of English: a study in subatomic semantics. Cambridge: MIT Press, 1990.

POLLOCK, J.-Y. Verb movment, universal grammar, and the structure of IP. Linguistic Inquiry, v. 20, n. 3, p. 365-424, 1989.

REICHENBACH, H. Elements of symbolic logic. New York: Free Press, 1966. 
SILVÉRIO, S. M. Orą̧ões encaixadas e o sistema tempo-aspectual: uma abordagem morfossintática. Curitiba: UFPR/ CNPq, 2001. (projeto de pesquisa).

STOWELL, T. Syntax of tense. Los Angeles: University of California, 1993. Manuscrito.

. The phrase structure of tense. Los Angeles: University of California, 1994. Manuscrito. 